\title{
Enacted Stigma, Problem Substance Use, and Protective Factors among Asian Sexual Minority Youth in British Columbia
}

\author{
Colleen Poon \\ McCreary Centre Society \\ Elizabeth Saewyc \& Weihong Chen \\ McCreary Centre Society \& University of British Columbia
}

\begin{abstract}
This study examined enacted stigma and problem substance use among Asian sexual minority youth and the buffering role of protective factors. Logistic regression analyses of a weighted sample of 5,423 Asian youth who completed the 2003 BC Adolescent Health Survey indicated that sexual minority youth were more likely to be victimized compared to heterosexual peers. Furthermore, protective factors, such as involvement in extracurricular activities or healthy connections to peers or school, reduced the likelihood of problem substance use, even among stigmatized youth. The study highlights the need to create safe, supportive school and community environments for Asian sexual minority adolescents.
\end{abstract}

Keywords: lesbian/gay/bisexual, adolescent, Asian Canadian, stigma, substance use, population surveys

Colleen Poon, PhD, McCreary Centre Society, Vancouver, BC; Elizabeth Saewyc, PhD, RN, FSAHM, McCreary Centre Society, Vancouver, BC, \& School of Nursing, University of British Columbia; Weihong Chen, PhD, McCreary Centre Society, Vancouver, BC, \& School of Nursing, University of British Columbia.

This study has been funded by grant \#R01 DA1797901 from the U.S. National Institute of Drug Abuse, NIH (Saewyc, PI), by grants \#HOA 80059 and \#CPP86374 from the Canadian Institutes of Health Research: Institute of Population \& Public Health, Institute of Gender \& Health, and Institute of Human Development, Child and Youth Health (Saewyc, PI). The authors would like to acknowledge The McCreary Centre Society, Vancouver, BC as the original source of the 2003 BC Adolescent Health Survey. This study has received ethics approval from the University of British Columbia Behavioural Research Ethics Board.

Correspondence regarding this article should be addressed to Dr. Elizabeth Saewyc, UBC School of Nursing, T201-2211 Wesbrook Mall, Vancouver, BC V6T 2B5. Telephone: 604-822-7505. Fax: 604-822-7466. Email: elizabeth.saewyc@nursing.ubc.ca 
Adolescents who hold a minority sexual orientation (such as lesbian, gay, or bisexual [LGB], or mostly heterosexual adolescents) face higher risks for victimization and compromised safety in Canadian society, in part due to the stigma associated with orientations that are not exclusively heterosexual (Chamberland, Émond, Julien, Otis, \& Ryan, 2010; Saewyc, Konishi, Poon, \& Smith, 2011; Taylor et al., 2010). This societal stigma can manifest as overt violence, rejection, and discrimination targeted toward sexual minority youth, that is, enacted stigma (Saewyc, Poon, Homma, \& Skay, 2008). It also shows up less directly, for example, when families, schools, and community groups withhold from sexual minority youth the social support and nurturing that are important factors for healthy development (Saewyc et al., 2009). This combination of higher victimization and reduced support has been linked to mental health inequities among sexual minority adolescents, including depression and suicidality (Espelage, Aragon, Birkett, \& Koenig, 2008; Saewyc, Poon, et al., 2007), as well as substance use and abuse (Espelage et al., 2008; Marshal et al., 2008). For adolescents, much of this enacted stigma takes place in school (Berlan, Corliss, Field, Goodman, \& Austin, 2010; Taylor et al., 2010).

Sexual minority youth who also come from an ethnic minority background must deal with two minority statuses, contributing to increased stress (Consolacion, Russell, \& Sue, 2004; Homma \& Saewyc, 2007). There is limited research, however, about the issues of sexual minority youth from ethnic minority backgrounds, especially Asian Canadian or Asian American adolescents. This paper examines stigma among Asian Canadian sexual minority youth by looking at their victimization experiences at school, the link between enacted stigma and problem substance use, and potential protective factors that reduce the odds of such problems, even among youth targeted by enacted stigma.

\section{Background}

Studies of enacted stigma involving sexual minority youth in Canada have investigated a range of experiences, including deliberate exclusion, homophobic bullying, physical and sexual assault, and discrimination (Chamberland et al., 2010; Saewyc, Poon, et al., 2007; Saewyc et al., 2011; Taylor et al., 2010). A study of more than 1,500 students from five high schools in a large central Canadian city found sexual minority youth were more likely to be bullied than their heterosexual peers (Williams, Connolly, Pepler, \& Craig, 2005). The first National Climate Survey on Homophobia in Canadian Schools, conducted in 2007, found pervasive levels of homophobic bullying toward sexual minority youth (Taylor et al., 2010). In a similar survey of Quebec high schools and CEGEPs conducted during the same year, Chamberland and colleagues (2010) reported equally widespread levels of harassment, assault, and rejection of sexual minority adolescents.

Victimization experiences help to explain associations between sexual orientation and health-compromising behaviours such as suicide attempts and substance use. Williams and colleagues (2005) found that victimization mediated the relationship between sexual orientation and depression, while others noted that sexual abuse history better explained differences in HIV risk behaviours, including injection drug use, among adolescents in western Canada (Saewyc et al., 2006) .

While protective factors, such as supportive family relationships, school connectedness, and caring nonfamily adults have been consistently shown to reduce suicidality and other mental health problems among adolescents in general, there has been much less research focused on the buffering effects of protective factors 
for sexual minority youth (Saewyc, 2007). One study in Minnesota found that when adolescents had high levels of some key protective factors, such as family and school connectedness, their odds of suicide attempts were significantly lower than among sexual minority peers without such supports (Eisenberg \& Resnick, 2006). A similar study in Canada, using the BC Adolescent Health survey data from 1998, likewise found family and school connectedness were protective against suicide attempts among bisexual boys and girls, even when they had experienced sexual abuse and reported current high levels of emotional distress (Saewyc, Poon, et al., 2007). The majority of these studies of sexual orientation, victimization, health inequities, and protective factors have included populations that are predominantly European-heritage or Caucasian, with limited analyses for other ethnic groups, especially Asian Canadian or Asian American sub-populations.

A focus on ethnic minority youth may be particularly relevant in British Columbia, where $25 \%$ of the population in 2006 consisted of visible minorities (Statistics Canada, 2008). Furthermore, Statistics Canada projects that in 2017 one in every three British Columbians will belong to a visible minority (Bélanger \& Malenfant, 2005). Among youth aged 15 to 24, those of East and Southeast Asian origin make up 20\% of the population (Statistics Canada, 2010).

In many Asian cultures, sex and sexual orientation are private subjects that are not openly discussed (Okazaki, 2002). Same-sex behaviour may be seen as violating traditional beliefs related to familial duty and maintaining face (Kimmel \& Yi, 2004) and heterosexism appears to be stronger in these cultures (Chung \& Katayama, 1998). Having a sexual minority orientation or identity may be especially challenging; in one study, Asian Canadian undergraduates who were recent immigrants were found to have more conservative attitudes toward homosexuality than Canadian-born or less recent immigrants (Meston, Trapnell, \& Gorzalka, 1998).

Few studies have examined victimization and safety among Asian LGB youth. A study from the U.S. National Longitudinal Study of Adolescent Health (Add Health) about school experiences among youth with dual minority statuses found that sexual minority youth reported more negative attitudes toward school, felt less socially accepted, felt students at school were prejudiced, and felt unsafe at school compared to opposite-sex-attracted youth (Russell \& Truong, 2001). Among the 1,145 Asian youth in the sample, however, orientation did not significantly differentiate youth on these measures.

Research on the link between sexual minority status and mental health issues in Asian adolescents, including problematic substance use, is just as limited. A follow-up analysis of mental health outcomes in the second wave of Add Health, for example, noted White, African American, and Latino-Hispanic sexual minority boys and girls reported higher levels of suicidal ideation, depressive symptoms, and lower selfesteem than their peers (Consolacion et al., 2004), but this was not the case for Asian/Pacific Islander youth. The sample size of Asian sexual minority youth in that study was quite small (only 65 adolescents), however, and the researchers suggested the analyses may have been under-powered. In Canada, an analysis of Asian students within the BC Adolescent Health Survey found students who identified as lesbian, gay, bisexual, or mostly heterosexual were more likely than their heterosexual peers to use alcohol, cannabis, and other illicit drugs (Homma, Chen, Poon, \& Saewyc, 2012).

We could find only one research study on the link between protective factors and mental health issues among sexual minority Asian youth. In a school-based census survey of Minnesota high school students with 3,800 Asian American adolescents, 91 of whom reported recent same-gender sexual partners, Homma 
and Saewyc (2007) found that sexual minority youth who felt safer at school, or experienced higher levels of family caring, reported higher self-esteem and lower emotional distress.

Asian youth differ widely in their levels of acculturation, language, and immigrant status. Some evidence suggests language spoken at home (as a measure of acculturation) may be associated with levels of victimization and school safety. Yu and colleagues found that Asian American youth who primarily spoke a language other than English at home were more likely to feel they did not belong at their school, did not feel safe at school, felt alienated from classmates, and were bullied (Yu, Huang, Schwalberg, Overpeck, \& Kogan, 2002; Yu, Huang, Schwalberg, Overpeck, \& Kogan, 2003). Similarly, Le and Stockdale (2008) found an association between acculturation and serious violence; however, this relationship was mediated by peer delinquency. In their review of the literature, Smokowski and colleagues found that much of the literature on acculturation and youth violence among Asian/Pacific Islander adolescents was based on a single sample from one city in California (Smokowski, David-Ferdon, \& Stroupe, 2009). Thus, more work in this area is needed.

The current study had three main research questions: First, are Asian sexual minority students in British Columbia more likely to experience enacted stigma or victimization experiences than heterosexual Asian boys and girls? Second, does enacted stigma help explain higher rates of problem substance use among Asian sexual minority youth? Finally, among Asian sexual minority adolescents, are there protective factors that lower the odds of problem substance use even when the adolescents experience enacted stigma? Based on the limited previous literature, we hypothesized that mostly heterosexual and LGB youth would report more victimization compared to heterosexual peers, and that the levels of victimization would be higher among less acculturated students. We also hypothesized that exposure to enacted stigma in school would predict problems related to substance use for sexual minority adolescents, but that higher levels of protective factors would reduce those odds, even for sexual minority Asian adolescents who experienced victimization in school.

\section{METHODS}

\section{Design and Measures}

This study was part of a larger international study that investigated stigma using data from schoolbased surveys involving Indigenous, Asian, and European-heritage youth from Canada, New Zealand, and the United States. The current paper reports the results for Asian youth from the western coastal province of British Columbia, Canada.

The British Columbia Adolescent Health Survey (BC AHS) is an omnibus survey of youth health, risk behaviours, and protective factors. In 2003, this 140-item paper-and-pencil, anonymous, voluntary questionnaire was administered to a cluster-stratified random sample of over 1,500 classes in grades 7-12 in public schools in the province. The provincial data were weighted by a Statistics Canada consultant to adjust for the probability of selection and non-response rates and to be representative of student enrolment at provincial and regional levels. Each school district determined whether participation required written parental consent or parental notification with student consent. The overall response rate for the survey was $76 \%$. More detailed discussions of the methodology have been published elsewhere (Saewyc, Taylor, Homma, \& Ogilvie, 2008; Saewyc, Poon, et al., 2008). 
Ethnicity was assessed with the question: What is your background? (Mark all that apply). For this study, Asian youth were defined as those who answered "East Asian (e.g., Chinese, Japanese, Korean, etc.)" or "Southeast Asian (e.g., Cambodian, Filipino, Indonesian, Vietnamese, etc.)." Because youth could choose more than one response, the sample of Asian youth included those who chose East Asian and/or Southeast Asian, regardless of the total number of ethnic identities endorsed. Thus, as with other studies (Consolacion et al., 2004) this study included multi-ethnic Asian adolescents.

Sexual orientation was assessed through self-labelling mapped onto attraction, a method that has been used in a variety of other studies in North America (Saewyc et al., 2004). Response options were "100\% heterosexual (attracted to persons of the opposite sex)"; "mostly heterosexual"; "bisexual (attracted to both males and females)"; "mostly homosexual"; "100\% homosexual ('gay/lesbian'; attracted to persons of the same sex)"; and "not sure."

The survey contained eight items about violence or discrimination youth had experienced in the past year. These included verbal sexual harassment; involvement in physical fights; discrimination due to race, sexual orientation, or physical appearance; and verbal harassment, physical assaults, and purposeful exclusion at school or on the way to/from school. Response options varied from yes/no to "never," "once or twice," and "three or more times." In order to obtain an overall enacted stigma score, responses to these items were dichotomized into yes/no and then the number of "yes" responses was totalled, reflecting the number of different types of enacted stigma youth reported in the past year. The score ranged from 0 (none of events reported) to 8 (all types of events reported). This score did not reflect the frequency of events, only that the events occurred at least once.

There were 11 items listing problems youth might have experienced during the past year because of using alcohol or drugs, such as passing out, damaging property, getting in a car accident, conflict with family or with friends, problems with school or work, problems with the police, etc. There was also the item "I used alcohol or drugs in the past year but none of these happened." Students could mark more than one item. For these analyses, problem substance use was defined as experiencing one or more problems in the past year as a result of alcohol or drug use.

For potential protective factors, the BC AHS contained three scales that have been used in other surveys of youth, including an 11-item family connectedness scale, a 5-item school connectedness scale, and a 7-item peers with healthy attitudes toward risky behaviours scale (Pettingell et al., 2008; Saewyc et al., 2009). The scales have demonstrated reasonable reliability and validity in the BC student population (Saewyc \& Homma, 2010). The survey also included questions about extracurricular activities, including weekly or more frequent involvement in sports with a coach; sports without a coach (such as bicycling \& skateboarding); dance or aerobics classes; art/drama/music classes or groups; clubs or youth groups such as Girl Guides; and hobbies.

\section{Sample}

The weighted sample for the Asian group included 6,325 students, representing an estimated 59,890 East Asian and Southeast Asian adolescents enrolled in schools in BC. When asked about their sexual orientation, $79.9 \%$ of boys and $74.3 \%$ of girls identified as $100 \%$ heterosexual (the "heterosexual" group), $4.4 \%$ of boys and $7.7 \%$ of girls identified as mostly heterosexual, and $1.6 \%$ of boys and $3.6 \%$ of girls identified 
as bisexual, mostly homosexual, or 100\% homosexual (the "LGB" group). Among LGB boys, 55.2\% were bisexual and $44.8 \%$ gay; and among LGB girls, $81.5 \%$ were bisexual and $18.5 \%$ lesbian. Youth were excluded from analyses if they did not respond to the sexual orientation item $(2.5 \%)$ or responded "not sure" (11.7\%). Students who responded that they were not sure of their sexual orientation were the youngest of all orientation groups. They were also more likely than those who identified as $100 \%$ heterosexual to be recent immigrants and to speak a language other than English at home. Thus, those who were not sure may not have understood the question, may not yet have thought about their orientation, or may be questioning their orientation. The final weighted sample consisted of 5,423 youth ( $52.4 \%$ boys, $47.6 \%$ girls).

Nearly all (98.0\%) Asian youth lived in urban areas, and 76.8\% of the sample came from three large urban school districts in the Vancouver metropolitan area. Nearly half of Asian youth spoke a language other than English at home most of the time, and $28.3 \%$ of boys and $22.9 \%$ of girls were recent immigrants (i.e., had lived in Canada for five years or less). Table 1 shows additional demographic characteristics among the sexual orientation groups.

\section{Analysis}

Analyses first aimed to determine differences between orientation groups on enacted stigma scores, then examined the relationship between enacted stigma and problem substance use and protective factors and problem substance use for sexual minority youth. Finally, they sought to determine probability of problem substance use based on varying combinations of the presence of stigma and protective factors for sexual minority youth. Due to maturational and gender differences associated with sexual orientation, analyses controlled for age, where possible, and were performed separately by gender. All analyses were conducted using SPSS (SPSS Inc., 2006). Note that a design effect was not evident for the sample of LGB youth, who were so dispersed throughout the classrooms as to approximate a simple random sample, and thus statistical software to adjust for the complex sampling plan was not needed.

For the first aim, differences in the prevalence of demographic characteristics were compared using chi square analyses, then differences between the orientation groups in individual stigma items were tested using logistic regressions controlling for age and language spoken at home, with the $100 \%$ heterosexual group as the referent. The mean enacted stigma scale was not normally distributed, being skewed toward no experiences of violence or discrimination; with unequal sample sizes and significantly different variances between orientation groups, the data did not fit necessary assumptions for analysis of covariance or linear regression. Therefore, differences in enacted stigma scores between the orientation groups were tested using the non-parametric Kruskal Wallis ANOVA for mean ranks.

To test the link between enacted stigma and problem substance use for sexual minority adolescents, we conducted logistic regressions, separately by gender, for the mostly heterosexual and for the LGB Asian students, where problem substance use was the outcome and enacted stigma the predictor, along with age as a covariate. Because sexual abuse has been consistently and strongly linked to substance abuse in other studies, we also included sexual abuse as an additional potential predictor in a combined logistic regression model. We did the same to test the link between problem substance use and protective factors, conducting individual age-adjusted logistic regressions for each protective factor. We standardized continuous measures 
ENACTED STIGMA AND ASIAN SEXUAL MINORITY YOUTH

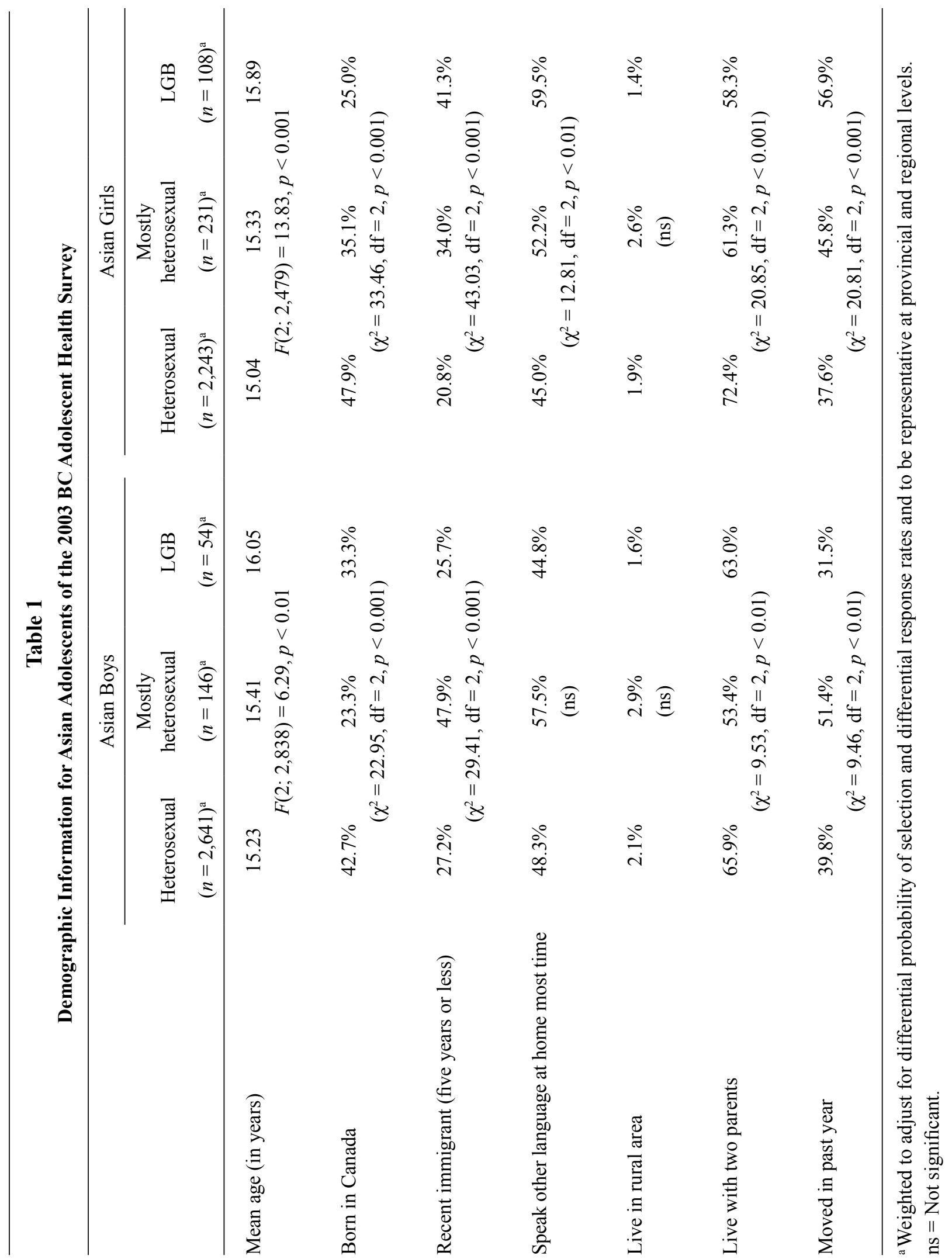


on a scale of 0 to 1 for the subsequent multivariate analyses, so that the odds ratios would be comparable across variables with different response ranges as well as between continuous and dichotomous variables.

Finally, we used probability profiling to explore the effects of varying combinations of risk and protective factors on problem substance use, with enacted stigma plus sexual abuse as the risk factors. First described by Rubenstein and colleagues (Rubenstein, Heeren, Housman, Rubin, \& Stechler, 1989), this method has been used with several other studies of both general adolescent populations and marginalized youth (see for example, Resnick, Ireland \& Borowsky, 2004; Pettingell et al., 2008). The procedure involved creating multivariate logistic regression models for each orientation group, of the combined risk and protective factors that were significant at the bivariate level, plus age as a covariate. The beta weights from this combined model, as well as the 10th and 90th percentile values of all the risk and protective factors in the model, were used to calculate individual probabilities of problem substance use based on different combinations of the presence (90th percentile) or absence (10th percentile) of the various risk and protective factors.

\section{RESULTS}

\section{Victimization Experiences}

With respect to the individual types of victimization (Table 2), LGB youth were 26 to 29 times more likely than their heterosexual peers to report being discriminated against due to their sexual orientation. Furthermore, the odds of being verbally sexually harassed, verbally harassed (teased) at school, and purposefully excluded at school were about twice as high for Asian LGB boys as heterosexual peers. Among Asian girls, the odds of being involved in physical fights, physically assaulted, or verbally harassed in the past year were at least 1.5 times as high for LGB youth as heterosexual peers. Dual minority discrimination may also be an issue for Asian LGB youth; among Asian LGB youth who had been discriminated against on the basis of race, the odds of also reporting sexual orientation discrimination was 17 times higher for boys and 4 times higher for girls, compared to peers who did not experience race discrimination (data not shown).

Mostly heterosexual Asian youth were more likely than their heterosexual peers to report stigmatizing events as well. Unlike LGB boys, however, mostly heterosexual boys were more likely than heterosexual peers to experience discrimination due to race but equally likely to experience discrimination due to sexual orientation. Among Asian girls, mostly heterosexual students were more likely than heterosexual peers to report most victimization experiences, except for physical fights and discrimination due to sexual orientation.

With respect to the frequency of speaking a language other than English at home (our only available proxy measure of acculturation), results suggest it was a significant predictor in only 5 of the 18 logistic regression models summarized in Table 2. Furthermore, in these cases, speaking a language other than English was not consistently associated with either lower or higher odds of being victimized. Thus, this predictor was not included in subsequent analyses.

The overall enacted stigma score ranked significantly higher for both mostly heterosexual and LGB boys and girls compared to heterosexual peers in the Kruskal-Wallis ANOVA test. Asian male LGB students had higher scores (mean rank, 1622) than mostly heterosexual peers (mean rank, 1611), who, in turn, had higher scores than heterosexual peers (mean rank, 1363; $\chi^{2}=18.07, \mathrm{df}=2, p<0.001$ ); however, a post-hoc 
ENACTED STIGMA AND ASIAN SEXUAL MINORITY YOUTH

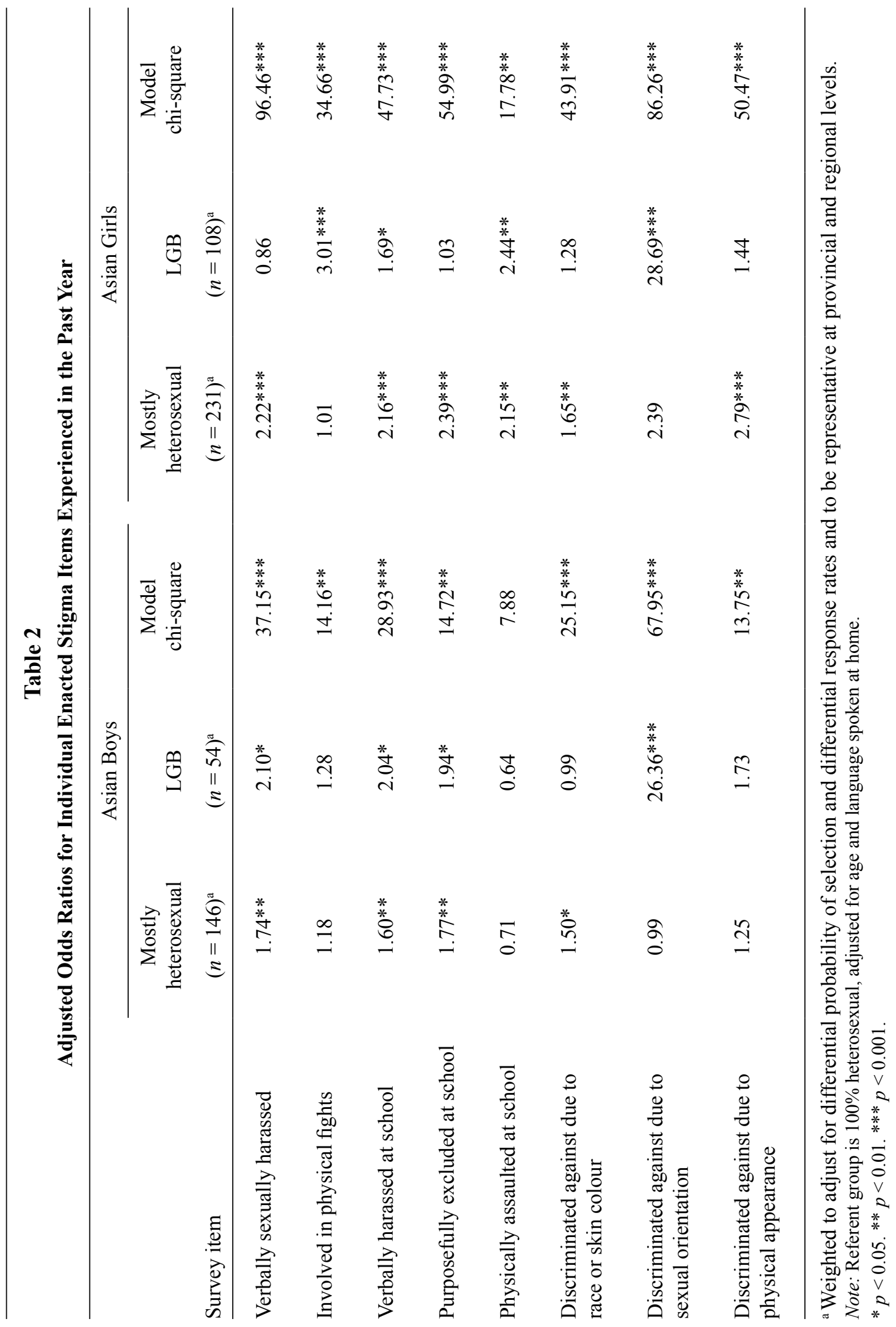


Mann-Whitney U test indicated the difference between LGB and mostly heterosexual groups was not significant. For Asian girls, LGB teens had higher ranks of enacted stigma scores (mean rank, 1395) compared to heterosexual peers (mean rank, 1210), but mostly heterosexual girls had the highest scores (mean rank, 1620; $\left.\chi^{2}=73.02, \mathrm{df}=2, p<0.001\right)$.

\section{Enacted Stigma, Sexual Abuse, Protective Factors, and Problem Substance Use}

Just over half of mostly heterosexual Asian boys had used alcohol or other drugs (52.7\%), and of these, $36.6 \%$ reported one or more problems due to substance use; similarly, of the $59.2 \%$ of LGB boys who had used alcohol or other drugs, $31.1 \%$ reported problem substance use. Nearly two-thirds of mostly heterosexual girls (61.3\%) and LGB girls (63.0\%) had ever used alcohol or other drugs, and among these, 37.8\% of mostly heterosexual girls and $20.9 \%$ of LGB girls reported problems with substance use.

Table 3 shows the bivariate and combined age-adjusted odds ratios of enacted stigma with sexual abuse history as predictors of problem substance use for mostly heterosexual and LGB Asian students, among those who had ever used alcohol or other drugs. It also shows the age-adjusted odds ratios of protective factors that significantly reduced the odds of problem substance use for each of these groups. Experiences of enacted stigma and sexual abuse history both strongly predicted problem substance use for all groups except LGB boys, where the sample size of those who reported both substance use and resulting problem substance use was quite small ( $<10$ cases) and so results may have been under-powered. (Sexual abuse also was not significantly associated with problem substance use at the bivariate level for the mostly heterosexual girls, so it was not included in their models). Even when combining enacted stigma and sexual abuse in the same model, the adjusted odds remained high (mostly heterosexual boys: enacted stigma, 12.40, sexual abuse, 6.69; LGB girls: enacted stigma, 94.40, sexual abuse, 14.92).

The probability profiles that were calculated from the combined models of risk factors and significant protective factors for mostly heterosexual boys, mostly heterosexual girls, and LGB girls are shown in Figures 1 to 3. Each of the figures shows the probabilities of problem substance use within each combination of risk factors, based on when youth have different types of protective factors. In Figure 1, for example, the bars at the bottom of the figure show the probability for students who report no risk factors with either no protective factors $(57 \%)$, weekly sports involvement $(23 \%)$, high school connectedness $(14 \%)$ or both protective factors (only 4\%). Similarly, the bars at the top of the figure show the probability of problem substance use when students have both high levels of enacted stigma and sexual abuse, with no protective factors (97\%), with sports involvement (88\%), with high school connectedness (80\%), and with both protective factors (48\%).

With high enacted stigma and no protective factors, the probability of sexual minority students reporting problem substance use was very high (97\% for mostly heterosexual boys, $74 \%$ girls, and $90 \%$ LGB girls). With even one protective factor, the probability was markedly reduced, and with both protective factors present, the probability was decreased by more than half. Even when students did not report high levels of enacted stigma or history of sexual abuse, in the absence of any protective factors, their probability of problem substance use was around $50 \%$ for mostly heterosexual students, and $10 \%$ for LGB girls, but with no risk factors and with high levels of protective factors, the probability was reduced to only $2 \%$ to $7 \%$. 
ENACTED STIGMA AND ASIAN SEXUAL MINORITY YOUTH

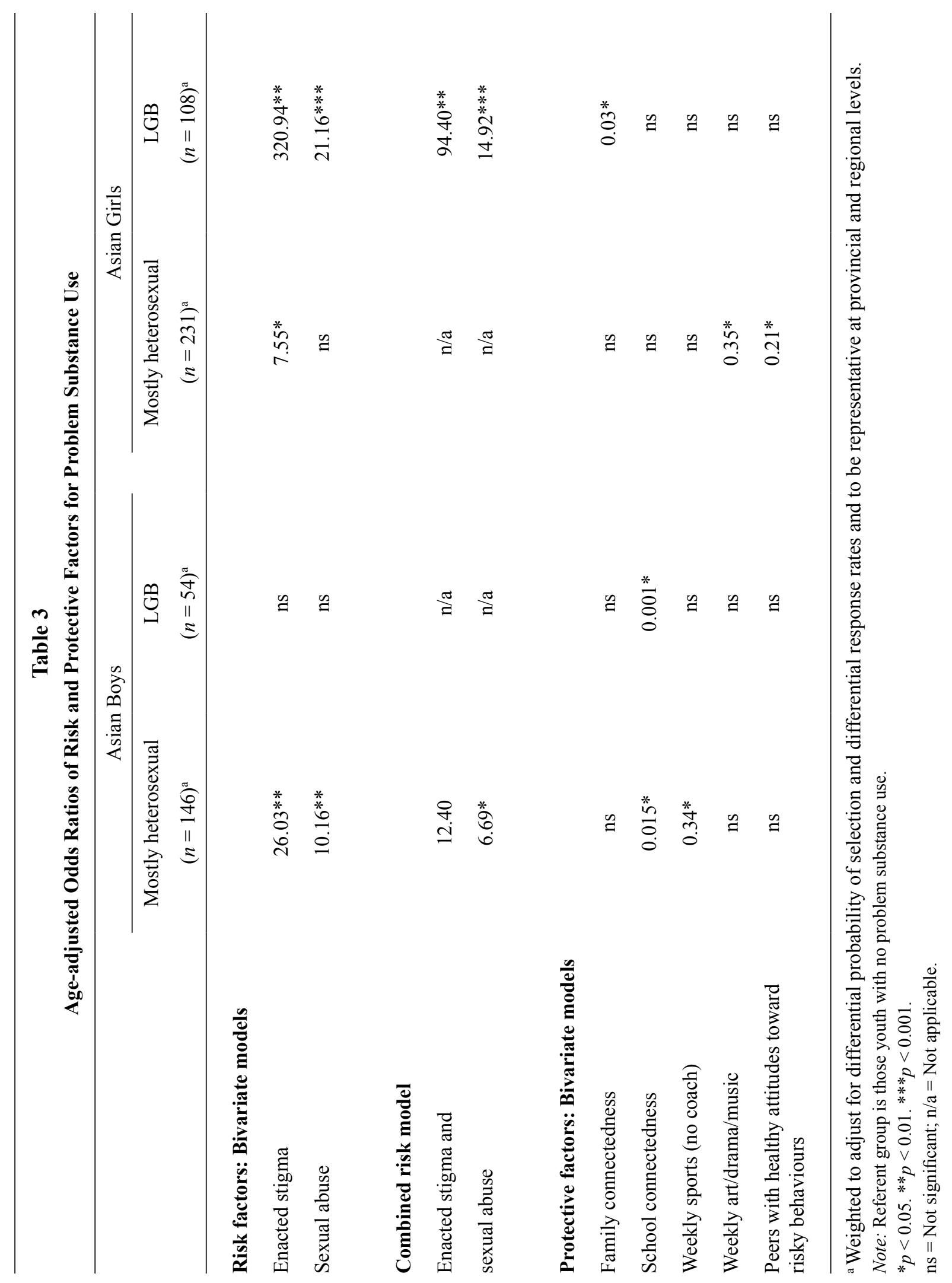




\section{Figure 1}

Probability of Problem Substance Use: Mostly Heterosexual Asian Boys

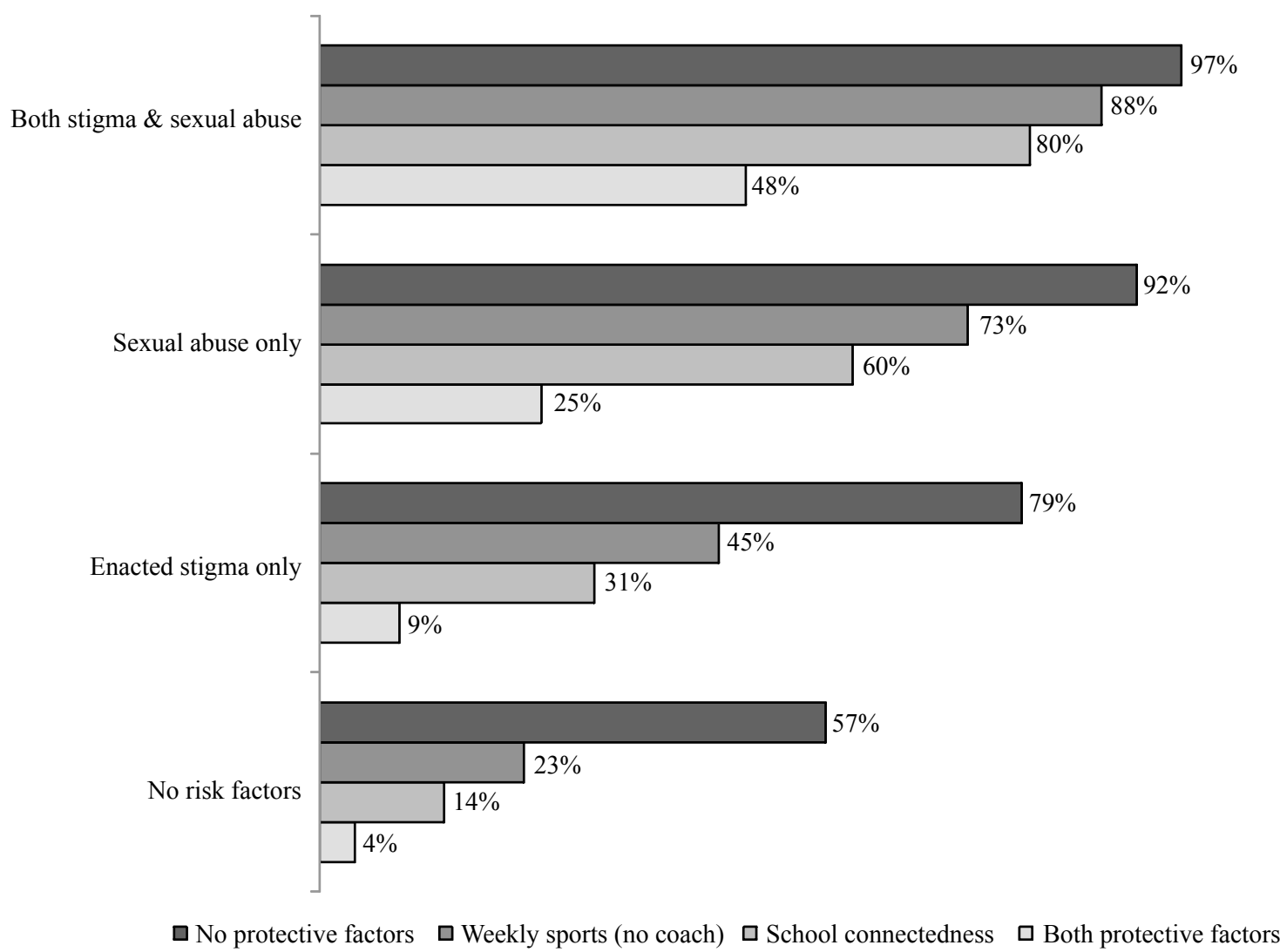

\section{DISCUSSION}

Sexual minority Asian youth in BC experienced more types of enacted stigma than their heterosexual peers. These experiences of harassment and discrimination were linked to problem substance use, although when sexual minority students had high levels of family or school connectedness and involvement in extracurricular activities, these appeared to buffer to some extent the increased risk of problem substance use from exposure to violence, whether enacted stigma in school or sexual abuse.

Our results among Asian Canadian adolescents were consistent with previous research in the general population, which has shown LGB and mostly heterosexual youth at greater risk for victimization (Berlan et al., 2010; Russell \& Truong, 2001; Saewyc et al., 2011; Taylor et al., 2010). Similarly, our findings suggest social supports, whether from family, school, or peers, may help buffer the psychological distress of enacted stigma for Asian Canadian adolescents, as other studies have suggested for general populations of students (Espelage et al., 2008; Taylor et al., 2010), and for Asian adolescents in the U.S. (Homma \& Saewyc, 2007). 
Figure 2

Probability of Problem Substance Use: Mostly Heterosexual Asian Girls

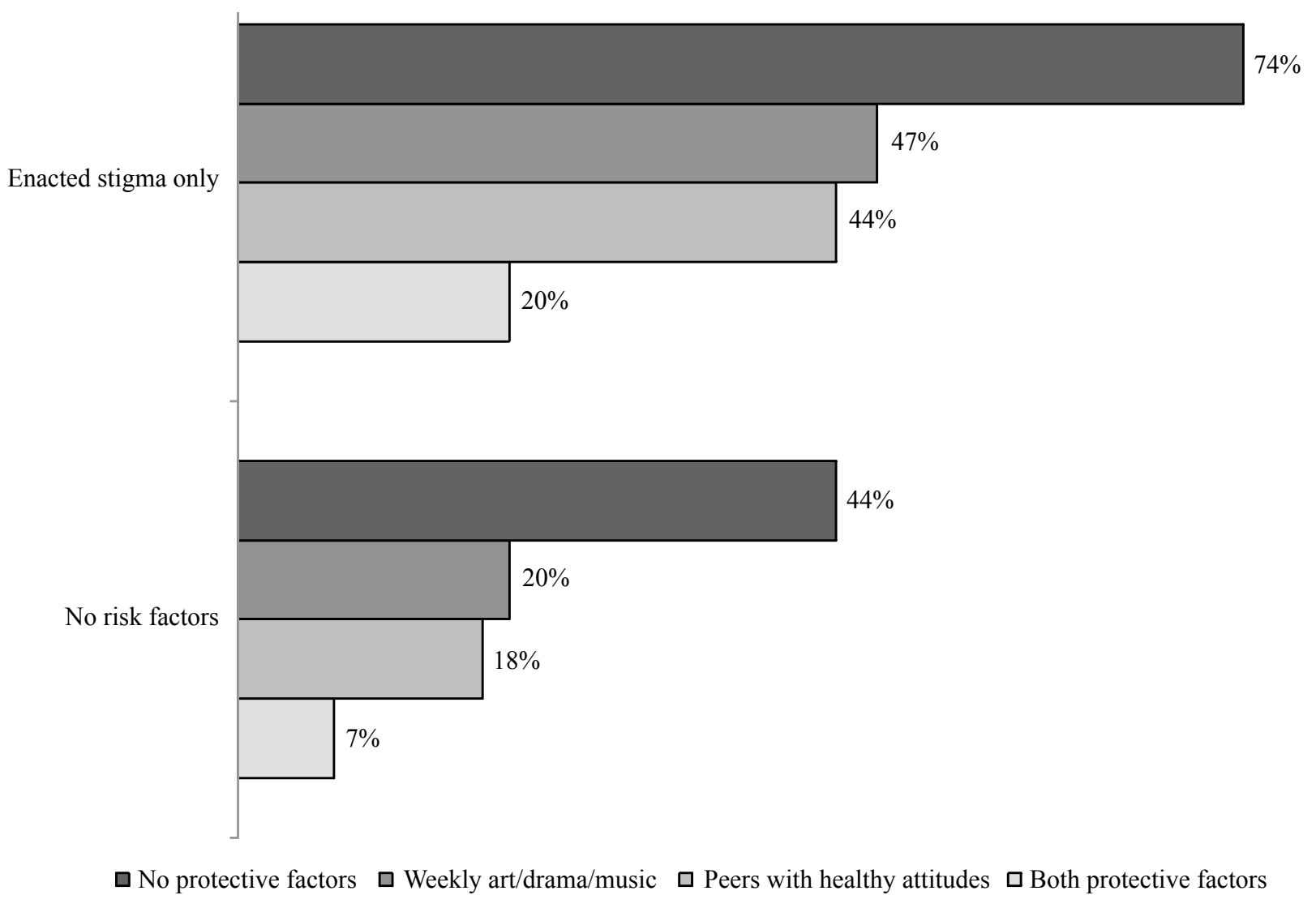

Mostly heterosexual girls experienced more different types of victimization than even lesbian and bisexual girls; however, due to the nature of the measure, it is not possible to determine whether they experienced a higher frequency of victimization. More research is needed to better understand youth who identify as mostly heterosexual youth (Ziyadeh et al., 2007). One study found that identification with this group was related to the "strength or frequency of their attractions to the opposite sex versus the same sex" (Austin, Conron, Patel, \& Freedner, 2007), although they still acknowledged attractions to both sexes. Since sexual orientation develops during the adolescent years, and stigma related to sexual minority orientations may make youth reluctant to identify as lesbian, gay, or bisexual, "mostly heterosexual" youth might be questioning their sexual orientation identity; in that case, our results would be consistent with those that found that questioning students experienced more bullying and homophobic victimization than either LGB or heterosexual students (Birkett, Espelage \& Koenig, 2009). On the other hand, a recent longitudinal study on the mobility of sexual orientation labelling suggests that mostly heterosexual youth are more likely to remain consistently identified as mostly heterosexual across adolescence and young adulthood, or to identify 
Figure 3

Probability of Problem Substance Use: Lesbian and Bisexual Asian Girls

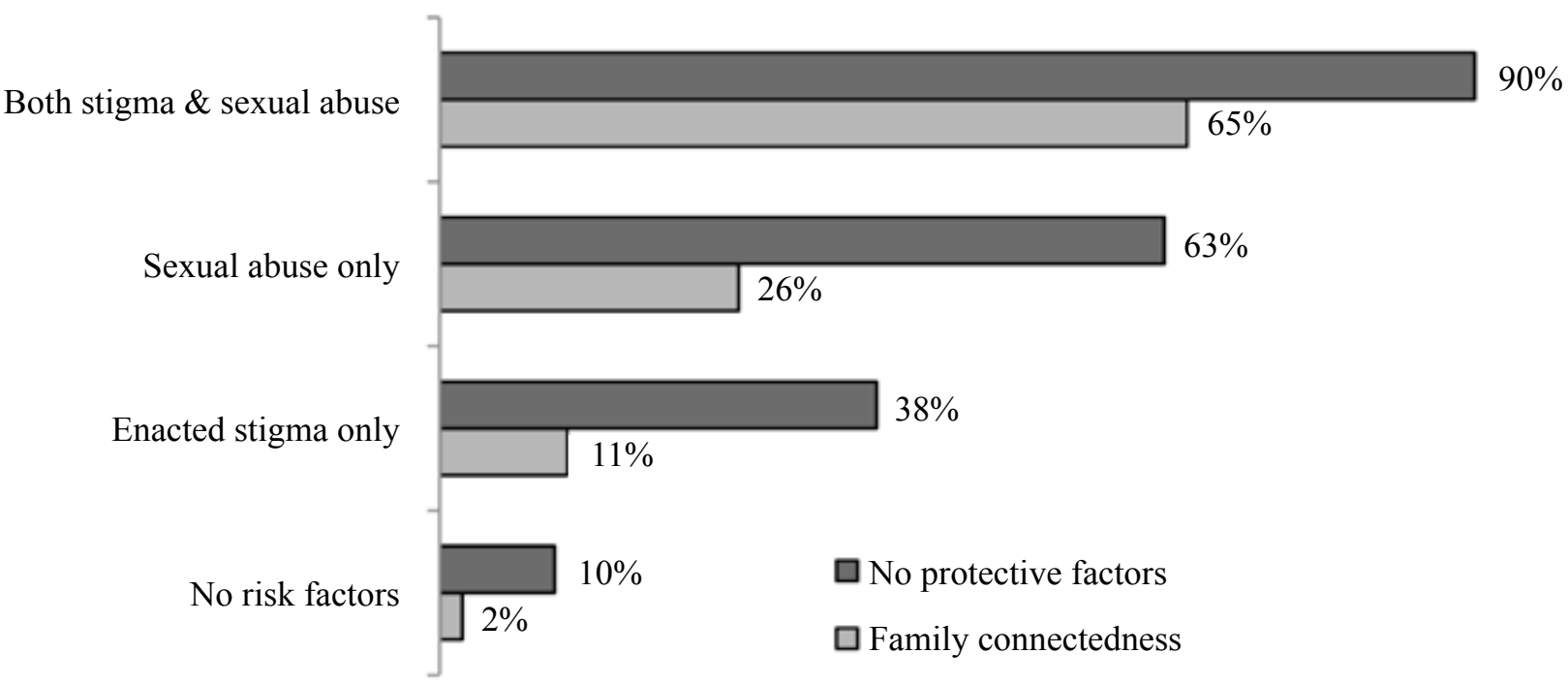

as completely heterosexual, rather than to identify as bisexual, lesbian, or gay (Ott, Corliss, Wypij, Rosario, $\&$ Austin, 2011). This would suggest that they should be considered a separate sexual minority identity category from lesbian, gay, or bisexual, although they also appear to be targeted, to some extent, for enacted stigma with other categories of sexual minority adolescents.

Although gay and bisexual Asian Canadian boys were significantly more likely to experience enacted stigma, this was not linked to problem substance use in our study. This is likely due to the small sample size of gay and bisexual Asian youth who used alcohol and drugs, and who reported problem substance use. Research with larger samples of gay and bisexual Asian adolescents may have power to show the same links to problem substances use as were found for mostly heterosexual boys and girls, as well as lesbian and bisexual girls, as these groups were at least twice as large as the gay and bisexual Asian group.

Another concern was the relatively limited number of protective factors that were significantly related to lower odds of problem substance use for any of the sexual minority groups of students. This may be because sexual minority youth have reported lower levels of protective factors in their lives compared to heterosexual teens (Saewyc et al., 2009; Williams et al., 2005). It is important to note, however, that when they did have higher levels of the significant protective factors, they had significantly lower probability of problem substance use, even if they had also experienced violence.

One of the strengths of this study is the data from a large-scale, population-based survey of adolescents in a region of western Canada that has a large proportion of Asian Canadian students. Most school-based surveys of youth in North America that include sexual orientation do not have adequate sample size or 
population diversity to study Asian sexual minority adolescents. At the same time, a limitation of our study is its definition of Asian, which includes a number of groups that differ in language, culture, and immigration history (Ozer \& McDonald, 2006), all of which may influence their experiences of stigma, social support, and substance use. Thus, there might be within-group differences that we could not explore with this data due to sample size issues. Other studies suggest that disaggregation of Asian youth yields significant variation within the group in areas such as victimization (e.g., Hishinuma et al., 2005). Since two-thirds of East and Southeast Asian youth aged 15 to 24 in British Columbia are Chinese (Statistics Canada, 2010), it is reasonable to assume the majority of students in our sample were of Chinese heritage and that our results may not generalize to other regions of Canada with different proportions of Asian cultural groups. Further research with other Asian samples, or with individual Asian ethnic groups (i.e., Chinese only, or Korean), may help to better delineate the nature of the relationship between sexual orientation, victimization, and substance use.

The results of this study suggest Asian sexual minority youth are at similar risk for stigma, but may require culturally sensitive services. Language barriers may be an issue, as more than one-fifth of the adolescents in our sample were recent immigrants, and more than half spoke a language other than English at home most of the time. In addition, speaking about matters related to sex, sexual orientation, and sexual abuse may be culturally taboo for some Asian youth; being lesbian, gay or bisexual may be especially difficult to discuss, as is disclosing sexual abuse, so school and health professionals need to consider how to be sensitive to their needs.

The British Columbia Human Rights Code protects individuals in public places, such as schools, from discrimination and harassment based on their sexual orientation (British Columbia Ministry of Attorney General, 2007). Furthermore, the education system has guidelines in place to address diversity and safety in schools (e.g., the BC Safe Schools Strategy, British Columbia Ministry of Education, 2004). Nevertheless, the results of the current study suggest that Asian LGB youth in British Columbia are the targets of stigma. Recent research has shown that students in more supportive schools, with policies addressing anti-gay bullying, identified supportive teachers, and groups such as Gay-Straight Alliances, rate their school climate more positively, and report lower levels of victimization (Birkett et al., 2009; Chamberland et al., 2010; Goodenow, Szalacha, \& Westheimer, 2006; Szalacha, 2003; Taylor et al., 2010). Fostering positive school climates, engaging sexual minority youth in extracurricular activities, and reducing homophobic bullying in schools may help prevent negative outcomes for sexual minority youth. This study further highlights the need to implement culturally diverse programs and policies to reduce sexual orientation stigma in schools, and to create safer school environments that are free from bullying, harassment, and violence for all youth.

\section{RÉSUMÉ}

Cette étude s'intéresse aux expériences de stigmatisation effective et à l'abus de substances toxiques chez les jeunes asiatiques de minorités sexuelles, ainsi qu'à l'effet tampon produit par des facteurs protectifs. Des analyses de régression logistique d'un échantillon pondéré de 5423 jeunes asiatiques ayant répondu au BC Adolescent Health Survey de 2003 indiquent que les jeunes de minorités sexuelles sont plus susceptibles d'être victimisés par rapport à leurs pairs hétérosexuels. De plus, certains facteurs protectifs, tel que la participation à des activités parascolaires ou des rapports robustes avec ses pairs ou le milieu scolaire, réduisent la probabilité d'abus de substances toxiques, même chez les jeunes qui sont stigmatisés. Cette 


\section{CANADIAN JOURNAL OF COMMUNITY MENTAL HEALTH}

étude souligne le besoin de mettre en place des milieux scolaires et communautaires qui soient sécuritaires et qui soutiennent les adolescents et adolescentes asiatiques de minorités sexuelles.

Mots clés : lesbiennes/gais/bisexuelles/bisexuels, jeunes, Canadiens d'origine asiatique, expériences de stigmatisation, toxicomanie, enquêtes en population

\section{REFERENCES}

Austin, S.B., Conron, K.J., Patel, A., \& Freedner, N. (2007). Making sense of sexual orientation measures: Findings from a cognitive processing study with adolescents on health survey questions. Journal of LGBT Health Research, 3(1), 55-65.

Bélanger, A., \& Malenfant, É.C. (2005). Population projections of visible minority groups, Canada, provinces and regions: 2001-2017, Statistics Canada Cat. No. 91-541-XIE. Ottawa, ON: Minister of Industry.

Berlan, E.D., Corliss, H.L., Field, A.E., Goodman, E., \& Austin, S.B. (2010). Sexual orientation and bullying among adolescents in the Growing Up Today Study. Journal of Adolescent Health, 46(4), 366-371.

Birkett, M., Espelage, D.L. \& Koenig, B. (2009). LGB and questioning students in schools: The moderating effects of homophobic bullying and school climate on negative outcomes. Journal of Youth \& Adolescence, 38, 989-1000.

British Columbia Ministry of Attorney General. (2007). Human rights in British Columbia: Discrimination based on sexual orientation. Victoria, BC: Ministry of Attorney General. Retrieved from http://www.ag.gov.bc.ca/humanrights-protection/pdfs/SexualOrientationDiscrimination.pdf

British Columbia Ministry of Education. (2004). Diversity in BC schools: A framework (March 2004 ed.). Victoria, BC: Author. Retrieved from http://www.bced.gov.bc.ca/diversity/diversity_framework.pdf

Chamberland, L., Émond, G., Julien D., Otis J., \& Ryan, B. (2010). L'impact de l'homophobie et de la violence homophobe sur la réussite et la persévérance scolaires, Rapport de recherche Action concertée sur la persévérance et la réussite scolaires MELS-FQRSC, Montréal, UQAM. Available at: http://www.fqrsc.gouv.qc.ca/fr/rechercheexpertise/projets/rapports-recherche.php\#PRS2006

Chung, Y.B., \& Katayama, M. (1998). Ethnic and sexual identity development of Asian-American lesbian and gay adolescents. Professional School Counseling, 1(3), 21-25.

Consolacion, T.B., Russell, S.T., \& Sue, S. (2004). Sex, race/ethnicity, and romantic attractions: Multiple minority status adolescents and mental health. Cultural Diversity and Ethnic Minority Psychology, 10(3), 200-214.

Eisenberg, M.E., \& Resnick, M.D. (2006). Suicidality among gay, lesbian and bisexual adolescents: The role of protective factors. Journal of Adolescent Health, 39, 662-668.

Espelage, D.L., Aragon S.R., Birkett, M., \& Koenig, B.W. (2008). Homophobic teasing, psychological outcomes, and sexual orientation among high school students: What influence do parents and schools have? School Psychology Review, 37(2), 202-216.

Goodenow, C., Szalacha, L., \& Westheimer, K. (2006). School support groups, other school factors, and the safety of sexual minority adolescents. Psychology in the Schools, 43(5), 573-589.

Homma, Y., Chen, W., Poon, C., \& Saewyc, E.M. (2012). Sexual orientation and substance use among East Asian high school students in British Columbia. Journal of Child and Adolescent Substance Abuse, 21, 32-50. doi: 10.1080/1067828X.2012.636687

Homma, Y., \& Saewyc, E.M. (2007). The emotional well-being of Asian-American sexual minority youth in school. Journal of LGBT Health Research, 3(1), 67-78.

Hishinuma, E.S., Chang, J.Y., Goebert, D.A., Else, R.N., Nishimura, S.T., Choi-Misailidis, S., . . Jones, L. M. (2005). Prevalence of victims of violence among ethnically diverse Asian/Pacific islanders. Violence and Victims, 20(5), 561.

Kimmel, D.C., \& Yi, H. (2004). Characteristics of gay, lesbian, and bisexual Asians, Asian Americans, and immigrants from Asia to the USA. Journal of Homosexuality, 47(2), 143-171.

Le, T.N., \& Stockdale, G. (2008). Acculturative dissonance, ethnic identity, and youth violence. Cultural Diversity \& Ethnic Minority Psychology, 14(1), 1-9.

Marshal, M.P., Friedman, M.S., Stall, R., King, K.M., Miles, J., Gold, M.A., . . Morse, J.Q. (2008). Sexual orientation and adolescent substance use: A meta-analysis and methodological review. Addiction, 103, 546-556. 


\section{ENACTED STIGMA AND ASIAN SEXUAL MINORITY YOUTH}

Meston, C.M., Trapnell, P.D., \& Gorzalka, B.B. (1998). Ethnic, gender, and length-of-residency influences on sexual knowledge and attitudes. Journal of Sex Research, 35(2), 176-188.

Okazaki, S. (2002). Influences of culture on Asian Americans' sexuality. Journal of Sex Research, 39(1), 34-41.

Ott, M.Q., Corliss, H.L., Wypij, D., Rosario, M., \& Austin, S.D. (2011). Stability and change in self-reported sexual orientation identity in young people: Application of mobility metrics. Archives of Sexual Behavior, 40(3), 519-532.

Ozer, E.J., \& McDonald, K.L. (2006). Exposure to violence and mental health among Chinese American urban adolescents. Journal of Adolescent Health, 39(1), 73.

Pettingell, S.L., Bearinger, L.H., Skay, C.L., Resnick, M.D., Potthoff, S.J., \& Eichhorn, J. (2008). Protecting urban American Indian young people from suicide. American Journal of Health Behavior, 32(5), 465-476.

Resnick, M.D., Ireland, M., \& Borowsky, I.W. (2004). Youth violence perpetration: What protects? What predicts? Findings from the National Longitudinal Study of Adolescent Health. Journal of Adolescent Health, 35(5), 424-433.

Rubenstein, J.L., Heeren, T., Housman, D., Rubin, C., \& Stechler, G. (1989). Suicidal behaviour in "normal" adolescents: Risk and protective factors. American Journal of Orthopsychiatry, 59, 59-71.

Russell, S.T., \& Truong, N.L. (2001). Adolescent sexual orientation, race and ethnicity, and school environments: A national study of sexual minority youth of color. In K.K. Kumashiro (Ed.), Troubling intersections of race and sexuality: Queer students of color and anti-oppressive education (pp. 113-130). Lanham, MD: Rowman \& Littlefield.

Saewyc, E.M. (2007). Contested conclusions: What claims can (and cannot) be made from the current research on gay, lesbian, and bisexual teen suicide attempts? Journal of LGBT Health Research, 3, 79-87.

Saewyc, E.M., Bauer, G.R., Skay, C.L., Bearinger, L.H., Resnick, M.D., Reis, E., \& Murphy, A. (2004). Measuring sexual orientation in adolescent health surveys: Evaluation of eight school-based surveys. Journal of Adolescent Health, 35, 345e.1-e.16, on-line at http://www.journals.elsevierhealth.com/periodicals/jah/issues

Saewyc, E.M., \& Homma, Y. (2010). Psychometric properties of scales in the BC Adolescent Health Surveys of McCreary Centre Society, 1998, 2003, 2008. [Technical report]. Vancouver, BC: McCreary Centre Society.

Saewyc, E.M., Homma, Y., Skay, C.L., Bearinger, L., Resnick, M., \& Reis, E. (2009). Protective factors in the lives of bisexual adolescents in North America. American Journal of Public Health, 99, 110-117. PubMedCentral ID\#: PMC2636603.

Saewyc, E.M., Konishi, C., Poon, C., \& Smith, A. (2011). Is it safer to be gay in high school today? Trends in sexual orientation identity and harassment in Canada. Journal of Adolescent Health, 48, S8-S9.

Saewyc, E.M., Poon, C., Homma, Y., \& Skay, C.L. (2008). Stigma management? The links between enacted stigma and teen pregnancy trends among gay, lesbian, and bisexual students in British Columbia. Canadian Journal of Human Sexuality, 17(3), 123-139.

Saewyc, E., Poon, C., Wang, N., Homma, Y., Smith, A., \& McCreary Centre Society. (2007). Not yet equal: The health of lesbian, gay, and bisexual youth in BC. Vancouver, BC: McCreary Centre Society.

Saewyc, E.M., Skay, C., Richens, K., Reis, E., Poon, C., \& Murphy, A. (2006). Sexual orientation, sexual abuse, and HIVrisk behaviors among adolescents in the Pacific Northwest. American Journal of Public Health, 96(6), 1104-1110.

Saewyc, E.M., Taylor, D., Homma, Y., \& Ogilvie, G. (2008). Trends in sexual health and risk behaviours among adolescent students in British Columbia. Canadian Journal of Human Sexuality, 17(1/2), 1-12.

Smokowski, P.R., David-Ferdon, C., \& Stroupe, N. (2009). Acculturation and violence in minority adolescents: A review of the empirical literature. The Journal of Primary Prevention, 30(3-4), 215-263. doi:10.1007/s10935-009-0173-0

SPSS Inc. (2006). SPSS for Windows. Chicago, IL: SPSS Inc.

Statistics Canada. (2008). Canada's ethnocultural mosaic, 2006 census (No. 97-562-X). Ottawa, ON: Minister of Industry.

Statistics Canada. (2010). Ethnic origin (247), generation status (4), single and multiple ethnic origin responses (3), age groups (9) and sex (3) for the population 15 years and over of Canada, provinces, territories, census metropolitan areas and census agglomerations, 2006 census - 20\% sample data. Retrieved November 29, 2010, from http://www12.statcan.ca/english/census06/data/topics/Print.cfm?PID=92339\&GID=838062\&D1=0\&D2=1\&D $3=0 \& D 4=0 \& D 5=0 \& D 6=0$

Szalacha, L.A. (2003). Safer sexual diversity climates: Lessons learned from an evaluation of Massachusetts safe schools program for gay and lesbian students. American Journal of Education, 110(1), 58.

Taylor, C., Peter, T., McMinn, T.L., Schachter, K., Beldom, S., Ferry, A. , . . Paquin, S. (2010). Every class in every school: The first national climate survey on homophobia in Canadian schools: Final report. Toronto, ON: Egale Canada. 
Williams, T., Connolly, J., Pepler, D., \& Craig, W. (2005). Peer victimization, social support, and psychosocial adjustment of sexual minority adolescents. Journal of Youth and Adolescence, 34(5), 471-482.

Yu, S.M., Huang, Z.J., Schwalberg, R.H., Overpeck, M.D., \& Kogan, M.D. (2002). Association of language spoken at home with health and school issues among Asian American adolescents. Journal of School Health, 72(5), 192-198.

Yu, S.M., Huang, Z.J., Schwalberg, R.H., Overpeck, M.D., \& Kogan, M.D. (2003). Acculturation and the health and well-being of U.S. immigrant adolescents. Journal of Adolescent Health, 33(6), 479-488.

Ziyadeh, N.J., Prokop, L.A., Fisher, L.B., Rosario, M., Field, A.E., Camargo, C.A., Jr, \& Austin, S.B. (2007). Sexual orientation, gender, and alcohol use in a cohort study of U.S. adolescent girls and boys. Drug and Alcohol Dependence, 87(2-3), 119-130. doi:10.1016/j.drugalcdep.2006.08.004 